\title{
Research on Oral History Studies Summary of Ethnic Areas of Mainland China in Recent Ten Years
}

\author{
Zhimin Lei, Jiayan Zhang \\ Sichuan Agricultural University, Chengdu, 611130
}

Keywords: Oral History Studies Summary, Ethnic Areas, Mainland China, Recent Ten Years

\begin{abstract}
In the past ten years, oral history research in ethnic areas of mainland China has achieved certain results. In theory, it focuses on exploring the preservation mechanism of oral historical archives. In practice, it focuses on a certain area, and the research topics have different focuses. However, there is disconnection between theoretical and practical research, and the influence of practical research results is greater than theoretical research. Therefore, it is necessary to improve the discourse system and implementation norms of the historical branch of oral history as soon as possible, not only to pursue the diversity of research results, but also to pay attention to the richness of "quality".
\end{abstract}

\section{Introduction}

"The oral history of the modern sense is marked by the establishment of the Department of Oral History of Columbia University in 1948"[1]. This year is the 60th anniversary of the birth of oral history as a discipline, in order to study the current status of oral history in China's ethnic regions. There is a clear and comprehensive grasp, the author collects and organizes relevant literature and materials, and makes a review and share with colleagues, in order to learn from each other and check for missing gaps.

\section{Research on Current Status of Oral History in Ethnic Areas of Mainland China}

\subsection{Research on Oral History Archives in Ethnic Areas}

"The oral file is a derivative developed along with the emergence of oral history and oral literature"[2]. Peng Yan and Zhu Huiling (2012) believe that because "there are only 21 ethnic groups in China's 55 ethnic minorities with their own national language" [3], the history, customs, production and life of various ethnic minority areas, It has long been circulated through oral methods, and it is urgent to establish an oral history protection mechanism to adapt to the digital age. Xu Kaiyan (2016) believes that "the research and development of oral literature resources in China is still in its infancy" [4], and this "sprout" in the field of archive management research shows that it can truly build a file into the archives field. There are few and few, and the study of oral archives in ethnic minority areas is even rarer. Huang Cunxun and Zhang Ruiju (2015) of Sichuan University believe that in order to construct the oral archives of ethnic minorities in the process of research, it is necessary to "divide the main body of responsibility, establish content topics, unify construction standards, build management mechanisms and integrate construction results". "[5]Other paths to achieve an orderly archiving and preservation of oral history materials in ethnic minority areas.

"Yunnan is the province with the most ethnic minorities in China, and there are 25 ethnic minorities, 16 of which are living across borders" [6]. Therefore, Yunnan is more representative in the oral history research of ethnic areas. Dr. Zhiyue (2013) of Yunnan University pointed out that the impact of globalization and modernization "especially some cultural heritages that rely on oral transmission and inheritance are facing severe challenges that are constantly disappearing or in an endangered situation" [7]. From the perspective of promoting the great development and prosperity of ethnic cultures, Chen Zidan (2013) believes that "the construction of archives resources should be promoted to the height of archival culture construction” [8], leading the new transcendence of 
oral history and archives in ethnic areas. Du Qing (2010) also takes Yunnan as a research perspective, and believes that because there are many ethnic minorities in Yunnan without words, "most of them inherit history with primitive forms such as knots and drawings" [9].

\subsection{Oral History and Culture Research in Representative Ethnic Areas}

According to the data of the sixth national census in 2010, the population of ethnic minorities in China reached 106.43 million, accounting for $8.41 \%$ of the total population of the country, an increase of 167,000 from the 15.32 million in the fifth national census in 2000. The largest number is Zhuang, with $16,926,381$ people, accounting for $1.2700 \%$ of the national population; the lowest number is Tatar, only 3,556, accounting for $0.0003 \%$ of the national population; and the number of unidentified ethnic groups is 640,101, accounting for the national population. $0.0480 \%$.

It is not difficult to see that the population of ethnic minority areas in China does not have ethnic affiliation, and there are still 640,000 people without ethnic affiliation. Peking University professor Ma Wei (2015) pointed out that "the cornerstone of the national system and national policy is 'national identification'” [10]. Qi Zhixiang (2006) based on the study of the oral history of the "national identification" of the Baoan nationality, using field investigations and oral interviews as a way to understand the ethnic consciousness and historical evolution of the Baoan people [11]; Ma Xuefeng (2013) On the basis of combing the historical literature and interviewing the actual identity to study the evolution of the Hui nationality in Yunnan, "to explore the human geography of the Hui people in Yunnan in the context of the introduction of modern nationalism into China" [12]; Jin Jinyu (2015) In "Historical Memory and Identity Reconstruction: A Historical Anthropological Study of the Identification of the Tu Nationality", the Oral History of the Tu Nationality "National Recognition" is taken as a research perspective to examine and reflect on the theory and practice of "national identification" in the middle of the 20th century. "To find out the crux of China's national problems and provide a way of thinking for solving the real national problems" [13].

In addition to the study of oral history of "national recognition" represented by Professor Ma Wei, and the study of the influence of cultural environment in ethnic areas on religious communication, such as Gao Zhiying and Liu Xiaopeng (2012) of Yunnan University The Southern Buddhism Cultural Circle in the Yunnan-China-Myanmar border area, "through the oral history of a Han Buddhist temple abbot in the Southern Buddhism Cultural Circle, explores the spread of foreign religions in the Southern Buddhism and its motivation" [14]; Scholars Lu Qun (2015) is based on the oral history analysis of the beliefs of the Sangzhi Bai nationality. He believes that the narrative about the memory of the 'Tusi' in the oral history of the Sangzhi Bai nationality reflects the relationship of ethnicity from 'conflict' to 'integration'[15]. Some scholars have presented the important role of the oral history method in ethnic areas in the research process based on the study of specific ethnic groups. Huang Zhiguo and Jia Wei (2011) used the oral history research method to pass through Guangxi Rongshui Miao Autonomous County. Investigate and put forward the viewpoint of the "four stages of national assimilation" in the Miao area [16]. Some scholars also study the cultural resources of local characteristics from the perspective of ethnic regional culture. For example, scholar Wu Jian (2014) takes the cultural construction of the salt wells in Tibet as a perspective, and through the oral interpretation of "salt culture", he learned that "the salt is the intermediary to realize self." The ways and means of cultural construction [17] fully demonstrate the importance of "media” in cultural areas for cultural exchange and construction.

\subsection{Oral History Study of Specific Groups in Ethnic Areas}

At present, when the academic circles conduct oral history research on ethnic areas, the main object of their interviews is to focus on the "big men" who have experienced important historical events. When conducting oral history research with specific groups in ethnic areas as interviewees, scholars have more research results on oral history of interviews with women, but other groups such as children and groups engaged in specific occupations have less research on oral history.

The research work on the oral history of women in ethnic areas is mainly from a small perspective. For example, Huang Xiurong (2013) of Southwest University combed the research results of the oral history of ethnic minority women in China, and believed that although some 
research results have been obtained, more ethnic minorities Women are restricted by language and words [18]. In addition, there are many surveys, interviews or interviews with women in ethnic areas as research objects, and on this basis, corresponding works have been formed. Yumin Min (2011) has gone through more than ten years of interviewing, recording and sorting out a large amount of literature materials. An oral history book reflecting the living conditions of women of different ethnic groups in Mongolia, "Egeji River - Oral History of 17 Mongolian Women", although there are only 17 oral articles, the history of each heroine in the book, " It constitutes the history of each family and even the entire Mongolian for more than a hundred years"[19], rich and lively; "The Memory of the Hand: The Life World of Two Miao Women" edited by Wang Xiaomei and Wang Jianping (2011) The mouth of the Miao women recorded the important role of the national culture of batik in the life of the Miao people. It also showed the process of selling batik by the two Miao people's batik masters, Yang Mei and Li Mei, who promoted batik dyeing and led other Miao sisters to join the batik [20].

\subsection{Application Research of Oral History Teaching Methods in History Classroom}

The history curriculum is an important course to develop students' sense of citizenship and historical responsibility. Lu Yongzhen (2017), a teacher at Kaili City No. 1 Middle School in Guizhou, who studies oral history as a method of history teaching, believes that in minority areas, the application of oral history to teaching can not only enrich the form and content of history teaching. Inspire students' desire to explore history, "has a more prominent role in the inheritance and protection of local culture and the cultivation of students' feelings in the homeland" [21].

\section{Problems and Prospects in the Study of Oral History in Ethnic Areas of Mainland China}

"In the context of informationization and globalization, many valuable oral history and culture have been lost or lost on the verge of death, and correspondingly a large gap in the academic research on the oral history of ethnic areas" [22]. Judging from the research results of current scholars, oral history research in ethnic areas has developed greatly, but it is still weak in terms of research perspective, scope, historical data research, standardization and systematization.

First, the research perspective and scope are relatively limited. The theoretical perspectives of scholars mainly focus on the elaboration and path exploration of oral history archives construction in ethnic areas, emphasizing the role of archives in the inheritance of historical and cultural heritage in ethnic areas, and highlighting the "digital network" in archive preservation and construction. The important role; the practical perspective is to go deep into the field, select a region or nation, and record the history, culture, and customs of the ethnic regions through oral interviews. In fact, "the advantage of oral history lies in the fact that ordinary people participate in the discourse construction of history" [23]. In the process of conducting oral history research in ethnic areas, the academic circles have narrower choices for the ethnic groups and groups to which the dictator belongs, so that research the scope is limited.

Second, the historical research of the research is slightly insufficient. Because oral history has the characteristics of memory, subjectivity, instability, and has not yet formed a complete discourse and disciplinary system in China, the research on the theory of oral history itself is relatively lagging behind. At present, the study of oral history spans various disciplines such as history, literature, art, education, ethnology, journalism, religion, and physical education. Respondents cover various industries. Among the existing research results, there are many names in oral history studies in ethnic areas, but in fact, the subjective emotions of many narrators are mixed, or the interviewers directly organize them into words according to the interviewer's oral recordings, and the relevant literatures are insufficiently researched.

Third, the degree of specialization of research needs to be improved. Influenced by the relatively lagging research of oral history theory, coupled with the large number of ethnic minorities in China, the wide range of distribution, and the constraints of realities such as topography, language, and economic development level, the current historical data of oral history in ethnic areas is scattered, and the results of practice are scattered. The influence is greater than the process of theoretical 
research, and the theoretical research and practical experience are out of touch. Specifically, scholars who conduct practical research in the study of oral history in ethnic areas, such as interviewers of oral processes, mostly focus on oral interviews and collating texts, and rarely conduct oral history theory in ethnic areas. The research of theoretical research, to a certain extent, lacks the practical experience of oral history research in ethnic areas. Therefore, the research results on the oral history of ethnic areas have a chaotic situation of "respectively fighting each other".

To this end, in the future study of oral history in ethnic areas, it is possible to "prescribe the right medicine." Broaden the thinking from the perspective of research; expand the geographical scope, and make the oral history research of various ethnic regions and ethnic minorities "spread everywhere"; on the theme, expand the research on the construction of oral history archives in ethnic areas to important historical events in ethnic areas. The Communist Party of China has studied ethnic work in ethnic areas and oral history teaching in ethnic areas in a certain period of time; in groups, the proportion of the lower-level people, such as the elderly, children, and professionals in specific fields, has served as a dictator. Only by opening up the research perspective, strengthening the interdisciplinary theoretical integration and communication, and realizing the diversity of the narrators in the ethnic areas, can more lively historical materials be enriched into the historical system of the past. After the research perspective is opened, it is necessary to focus on collecting relevant arguments during the research process. After the interview, it is necessary to identify and distinguish the part of the interview with the subjective sentiment of the oral person; pay attention to collecting the historical materials of the interviewee and the local history. Reduce the impact on the authenticity and integrity of the oral content caused by the personal experience of the dictator and local environmental factors. In addition, it is necessary to combine the study of oral history theory and practical research in ethnic areas, enhance the normativeness of practical research in theoretical research, sum up experience and form new theoretical results, in order to gradually enhance the systematic nature of oral history research in ethnic areas.

\section{Acknowledgements}

Fund Project: This article is the Sichuan Agricultural University Social Science Association Project "The application of the national policy of the Communist Party of China in the northwestern Sichuan Province in the early days of the founding of New China and its basic experience- — The phased achievement of the black water raft as the research center, project number 2018ZD05

\section{References}

[1] Wang Jun. A Summary of the Research Status of Oral History in Mainland China[J]. Culture and Art Research, 2009, 2(03): 39-42.

[2][4] Xu Kaiyan. Research on the Inheritance of National Culture in Oral Archives in Minority Areas[J]. Lantai World,2016(04):79-81.

[3] [22] Peng Yan, Zhu Huiling. Research on the Excavation and Digital Preservation Model of Minority Oral History_-Taking Tujia Nationality in Wuling Mountain Area as an Example[J]. Researches in Library Science,2012(10):43-45+ 49.

[5] Huang Cunxun, Zhang Ruiju. A Macroscopic Exploration of the Orderly Construction of Oral History Files of Ethnic Minorities[J]. Guizhou Ethnic Research, 2015, 36(11): 196-199.

[6] Chen Jiandong. Yunnan Province was identified by the National Archives Bureau as a pilot area for the rescue and protection of ethnic minority oral history archives [J]. Lantai World, 2010 (07): 39.

[7] ZI Zhiyue. Research on the Development and Utilization of Oral Documents of Ethnic Minorities in Yunnan [D]. Yunnan University, 2013. 
[8] Chen Zidan. Thoughts on Constructing the Multi-ethnic Archives Resource System in Border Areas_—_Taking Yunnan as an Example[J]. Archives Research,2013(06):26-29.

[9] Du Qing. China and New Zealand work together to create a new model for the rescue of ethnic minority oral history files [N]. China Archives, 2010-07-29(001).

[10] Ma Wei. A Study of the Oral History of the Work of "National Identification"——The Preface to Lu Lu's "From Gui Province to Zhuang Xiang"[J]. Northwest Ethnic Studies, 2015(04): 5-15+222.

[11] Zhai Zhixiang. Self-identity and social definition of ethnic group ownership_—A special study on Baoan people [M]. Beijing: Nationalities Publishing House. 2006.

[12] Ma Xuefeng. From the teaching to the nation - the ethnic history of a minority community in the southwestern border [M]. Beijing: Social Sciences Academic Press. 2013.

[13] Zhai Jinyu. Historical Memory and Identity Reconstruction: A Historical Anthropological Study of the Identification of the Tu Nationality [M]. Beijing: Xueyuan Publishing House. 2015.

[14] Gao Zhiying, Liu Xiaopeng. The Same Symbiosis and Harmony--A Study of the Oral History of a Han Buddhism Monastery in the Southern Buddhism Cultural Circle[J]. Journal of Southwest Frontier Ethnic Studies,2012(02):174-180.

[15] Lu Qun. The Relationship between Tusi Regime and National Relationship_-Based on the Oral History of Sangzhi Bai Nationality's Belief[J]. Qinghai Ethnic Research,2015,26(02):27-31.

[16] Huang Zhiguo, Jia Wei.The Historical Evolution of Multi-ethnic Villages in Border Areas from the Perspective of Oral History_—A Case Study of Pedi Village, Antai Township, Rongshui County, Guangxi Province[J]. Guangxi Ethnic Studies,2011(04):138- 143.

[17] Wu Jianli. Culture, History and "Salt"__ A Survey of the Oral History of Salt Culture in Salt Wells in Tibet[J]. Cultural history,2014(06):97-102.

[18] Huang Xiurong. Research on Oral History Method and History of Chinese Minority Women[J]. Journal of Southwest University (Social Science Edition), 2013, 39(04): 150-154+176.

[19] Valuable. Eji River - the oral history of 17 Mongolian women [M]. Beijing: National Publishing House, 2011.

[20] Wang Xiaomei, Wang Jianping. The memory of the hand: the life world of two Miao women [M]. Guiyang: Guizhou University Press, 2011.

[21] Lu Yongzhen. The Practice of Oral History Courses in Middle Schools in Ethnic Areas_- Taking the Miao and Dong Ethnic Groups in Southeast Guizhou Province as an Example[J]. Basic Education Reference, 2017(07):26-27.

[23] Wang Yuying. Hot Spots and Orientation of Oral History Research in Recent Years[J]. Chongqing Social Sciences,2011(05):107-110. 